\title{
Effects of anesthesia on fluid volume kinetics after infusion of colloid solution during blood donation
}

\author{
Eun Ho Lee ${ }^{1}$, Sun-Key Kim ${ }^{1}$, Young Goo Yeo ${ }^{2}$, and Kyu Taek Choi ${ }^{1}$ \\ ${ }^{1}$ Department of Anesthesiology and Pain Medicine, Asan Medical Center, University of Ulsan College of Medicine, ${ }^{2}$ Hanyang \\ University College of Engineering, Seoul, Korea
}

Background: The fluid kinetics of intravenously infused colloid during inhalation anesthesia and hemorrhage have not been investigated. We therefore assessed fluid space changes during infusion of hydroxyethyl starch solution after hemorrhage in conscious and desflurane-anesthetized individuals.

Methods: Following the donation of $400 \mathrm{ml}$ of blood, $500 \mathrm{ml}$ of hydroxyethyl starch solution was infused over 20 minutes into wakeful and desflurane-anesthetized volunteers. Blood was repeatedly sampled to measure hemoglobin concentration, a marker of plasma dilution, and fluid kinetic analysis was performed to evaluate changes in fluid space.

Results: Using a fluid kinetic model, we found that the mean volume of fluid space was 7,724 $\pm 1,788 \mathrm{ml}$ in wakeful volunteers and 6,818 $\pm 4,221 \mathrm{ml}$ in anesthetized volunteers, and the elimination rate constants were $7.1 \pm 3.5 \mathrm{ml} / \mathrm{min}$ and $19.4 \pm 4.6 \mathrm{ml} / \mathrm{min}$, respectively.

Conclusions: Infusion of colloid after mild hemorrhage resulted in similar expansions of plasma volume in desfluraneanesthetized and conscious individuals. During anesthesia, however, the expansion of plasma volume by colloid was decreased and of shorter duration than observed in conscious patients. (Korean J Anesthesiol 2010; 58: 514-520)

Key Words: Fluid therapy, General anesthesia, Hemorrhage, Hydroxyethyl starch solution.

\section{Introduction}

During surgery, appropriate administration of intraoperative fluids is important for maintaining cardiac output and tissue perfusion under conditions of ongoing fluid and electrolyte loss. Intravenously administered fluids may be crystalloid or colloid solutions, and the ability of a given fluid to expand intravascular volume can be influenced by many factors, including the type of infused fluid, the chosen form of anesthesia, and the volume status of the patient [1-3]. In a normovolemic state, anesthetics can alter the fluid kinetics of a crystalloid solution, by increasing the volume of distribution and decreasing the rate of excretion.

Received: December 3, 2009. Revised: 1st, January 4, 2010; 2nd, March 5, 2010. Accepted: April 8, 2010.

Corresponding author: Kyu Taek Choi, M.D., Ph.D., Department of Anesthesiology and Pain Medicine, Asan Medical Center, University of Ulsan College of Medicine, 388-1, Pungnap-dong, Songpa-gu, Seoul 138-040, Korea. Tel: 82-2-3010-3857, Fax: 82-2-470-1363, E-mail: qtek@amc.seoul.kr The results from this study have been presented at the $85^{\text {th }}$ Annual Scientific Meeting of The Korean Society of Anesthesiologists, November 6, 2008. (c) This is an open-access article distributed under the terms of the Creative Commons Attribution Non-Commercial License (http:// creativecommons.org/licenses/by-nc/3.0/), which permits unrestricted non-commercial use, distribution, and reproduction in any medium, provided the original work is properly cited. 
These changes may promote intravascular fluid retention and peripheral fluid accumulation [3,4]. To compensate for lost blood volume after hemorrhage, extravascular fluid is mobilized into the vascular tree by a spontaneous process termed "transcapillary refill", and urinary output is suppressed [5]. Anesthetics per se inhibit transcapillary refill and delay urinary excretion $[3,6,7]$. Hemorrhage can also lead to intravascular retention of fluids, primarily caused by a reduction in the elimination rate constant $[4,8,9]$. Because anesthesia impairs transcapillary refill after hemorrhage [6], infusion of crystalloid solution to correct hypovolemia can lead to a higher level of extravascular water retention during anesthesia than is seen in wakeful subjects. Under conditions of combined hemorrhage and anesthesia, however, less tissue edema has been observed following infusion of colloid compared with crystalloid solution [10]. This is primarily attributable to a greater retention of colloid solution in the intravascular space, and a decrease in the volume of colloid solution exiting to the interstitial fluid.

To quantify the effects of desflurane anesthesia on the kinetics of infused colloid, we analyzed and compared the distribution and elimination of $6 \%(\mathrm{w} / \mathrm{v})$ hydroxyethyl starch, dissolved in a balanced electrolyte solution (Hextend ${ }^{\circledR}$, BioTime Inc, Berkeley, CA), in anesthetized and wakeful mildly hypovolemic volunteers using a fluid kinetic model [11]. Employing a computerized simulation procedure and with input of parameters obtained by kinetic analysis, we also calculated the optimal rates of infusion required to yield predetermined dilution levels in anesthetized and wakeful volunteers.

\section{Meterials and Methods}

Sixteen healthy volunteers were recruited and divided into two groups of 8 subjects, a wakeful blood donor group (wakeful group, $\mathrm{n}=8$ ) and an anesthetized bone marrow (BM) donation group (anesthetized group, $\mathrm{n}=8$ ). The health status of each donor was assessed by history-taking, physical examination, and laboratory tests. All participants fasted overnight. The study protocol was approved by the Review Board of our institution, and all volunteers provided written informed consent.

Upon arrival in the blood donation room, both antecubital veins of individuals in the wakeful group were catheterized for blood donation and fluid infusion, followed by radial artery catheterization for blood sampling and continuous blood pressure monitoring. After completing donation of 1 unit (about $400 \mathrm{ml}$ ) of blood, each volunteer was intravenously infused with $500 \mathrm{ml}$ of Hextend ${ }^{\circledR}$, at a constant rate, over 20 minutes, via an infusion pump.

Individuals in the anesthetized group were denied fluids until $7 \mathrm{AM}$ of the study day, at which time they were given Hartmann solution at a rate of $100 \mathrm{ml} / \mathrm{h}$, followed by induction of anesthesia at $8 \mathrm{AM}$. The total volume of Hartmann solution infused until the end of induction was less than $200 \mathrm{ml}$, and fluid infusion was stopped when BM donation was completed. Anesthesia was induced with a bolus injection of thiopental sodium $5 \mathrm{mg} / \mathrm{kg}$, rocuronium $0.5 \mathrm{mg} / \mathrm{kg}$, and maintained with $6 \%$ desflurane-inspired concentration, $\mathrm{N}_{2} \mathrm{O}$ at $1 \mathrm{~L} / \mathrm{min}$, and $\mathrm{O}_{2}$ at $1 \mathrm{~L} / \mathrm{min}$. As in the wakeful group, antecubital veins and radial arteries were catheterized for fluid infusion, blood pressure monitoring, and blood sampling. When under anesthesia, each individual in the anesthetized group donated 1,200 $\mathrm{ml}$ of BM, with $800 \mathrm{ml}$ of autologous blood being administered during the procedure. After completion of BM donation, $500 \mathrm{ml}$ of Hextend ${ }^{\circledR}$ was infused, as in the wakeful group.

To calculate the changes in blood volume, we used hemoglobin $(\mathrm{Hb})$ dilution method. The $\mathrm{Hb}$ concentration was measured using $1 \mathrm{ml}$ arterial samples. At the time of each blood sampling, an initial volume of $2 \mathrm{ml}$ of arterial blood was withdrawn for avoiding any contamination of the sample with other fluids. After a blood sample was drawn, the catheter was then flushed with 1-2 ml of heparinized saline and the withdrawn blood was discarded. In wakeful group, blood sampling was done before fluid infusion and at $0,5,10,15$, $20,25,30,40,50,60,80,100,120,150$ and 180 minutes after infusion started. Sampling was performed in anesthetized group before fluid infusion and at $0,5,10,15,20,25,30,40,50$, 60, 80, 100 minutes after infusion started.

The distribution of the infused colloid was analyzed separately for the awake and anesthetized group using previously published one-compartment volume kinetic model [11-13], which can be summarized as follows: the infused fluid volume at a rate ki is distributed in an expandable body fluid space $(v)$, which the fluid space strives to maintain at a target (baseline) volume $(V)$. Fluid leaves the space at a fixed basal rate $(k \mathrm{~b})$, which represents baseline urinary excretion and evaporation to be $0.4 \mathrm{ml} / \mathrm{min}$ [14] and at a controlled rate proportional with a constant $(k r)$ to the deviation from the target volume, $V$.

The dilution of plasma determined from blood samples was assumed to reflect an increase in the volume of expandable body fluid spaces. As plasma volume is a component of $V$, the dilution of plasma at time $t$ was used to calculate $(\nu(t)-V) / V$ using the formula:

$$
(v(\mathrm{t})-V) / V=\left[\left(\mathrm{Hb}_{0} / \mathrm{Hb}_{\mathrm{t}}\right)-1\right] /(1-\text { baseline hematocrit })
$$

Baseline blood volume before fluid infusion $\left(\mathrm{BV}_{0}\right)$ and blood volume $\left(\mathrm{BV}_{\mathrm{t}}\right)$ at any time $(\mathrm{t})$ during fluid infusion were calculated as follows [13]:

$$
\begin{aligned}
\mathrm{BV}_{0}(\mathrm{~L})= & 0.03219 \times \text { body weight }(\mathrm{kg})+0.3669 \times \text { height }^{3}(\mathrm{~m}) \\
& +0.6041(\text { for males }), \text { or } \\
\mathrm{BV}_{0}(\mathrm{~L})= & 0.033308 \times \text { body weight }(\mathrm{kg})+0.3561 \times \text { height }^{3}(\mathrm{~m}) \\
& +0.1833(\text { for females }) .
\end{aligned}
$$


Baseline plasma volume was calculated by multiplying the baseline blood volume by ( 1 - hematocrit):

$\mathrm{BV}_{\mathrm{t}}=\mathrm{BV}_{0} \times$ hemoglobin $_{0} /$ hemoglobin $_{\mathrm{t}}$

The following equation describes the volume change in $v$ : $\mathrm{dv} / \mathrm{dt}=k \mathrm{i}-k \mathrm{~b}-k \mathrm{r}(v-V / V)$.

The unknown parameters $v, V$ and $k \mathrm{r}$ were calculated by nonlinear least-squares regression using Matlab Version 6.8 (Math Works Inc., Natick, MA, USA). This program was also used in simulations and to create nomograms to identify combinations of infusion rates and infusion times producing a predetermined dilution of $V$ [15]. The mean values of parameters obtained in the one-volume fluid space model were used to determine fluid regimens resulting in dilutions of $2 \%$, $5 \%, 10 \%, 15 \%, 20 \%$, and $25 \%$. Simulations were also utilized to determine infusion rates that would maintain a steady-state dilution after target dilution had been attained.

All data are presented as means \pm standard deviations (SD). Intergroup comparisons were performed using the MannWhitney test or the Wilcoxon Signed Rank test, and intra-group time-related variations were analyzed by repeated-measures analysis of variance. $\mathrm{P}<0.05$ was considered statistically significant.

\section{Results}

The withdrawal of $400 \mathrm{ml}$ blood (inducing mild hypovolemia) was generally well tolerated [14]. There were no major adverse events and hemodynamic measurements remained constant throughout the study period in both groups. Rapid infusion of fluid produced no symptoms.

Three volunteers in the anesthetized group were excluded from final analysis because their volume kinetics could not be analyzed. Thus, eight wakeful and five anesthetized volunteers were included in analysis. There were no statistically significant intergroup differences in age, body weight, height, or baseline $\mathrm{Hb}$ concentration (Table 1 ). In both groups, $\mathrm{Hb}$ concentration decreased significantly during fluid infusion, with the maximal dilution of $\mathrm{Hb}$ observed 5 minutes after completion of fluid

Table 1. Demographic and Fluid Kinetic Data in Wakeful and Anesthetized Volunteers

\begin{tabular}{lcc}
\hline & Wakeful group $(\mathrm{n}=8)$ & Anesthetized group $(\mathrm{n}=5)$ \\
\hline Age (years) & $29(29-30)$ & $35(28-37)$ \\
Gender (M/F) & $8 / 0$ & $4 / 1$ \\
Weight (kg) & $73(68-75)$ & $67(64-70)$ \\
Height $(\mathrm{cm})$ & $173(172-176)$ & $171(163-172)$ \\
\hline
\end{tabular}

Data are median and interqurtile range, or number of patients. infusion, or 25 minutes after commencement of fluid infusion, increasing gradually thereafter (Table 2).

The target (baseline) volumes (the $V$ values), as determined by volume kinetic analysis, were similar in the wakeful $(7,724$ $\pm 1,788 \mathrm{ml})$ and anesthetized $(6,818 \pm 4,221 \mathrm{ml})$ groups. In contrast, the elimination rate constant ( $\mathrm{kr}$ ) was significantly higher in the anesthetized $(19.4 \pm 4.6 \mathrm{ml} / \mathrm{min})$ than in the wakeful $(7.1 \pm 3.5 \mathrm{ml} / \mathrm{min})$ group $(\mathrm{P}<0.01)$ (Fig. 1).

Peak blood volume expansion $\left(\mathrm{BV}_{\mathrm{t}}-\mathrm{BV}_{0} / \mathrm{BV}_{0}\right)$ in both groups occurred 10 minutes after completion of fluid infusion (at 30 minutes), being $12.3 \pm 3.4 \%$ in the wakeful and $14.6 \pm 9.7 \%$ in the anesthetized group. In the wakeful group, this increase was maintained at both 60 minutes $(11.3 \pm 2.8 \%)$ and 180 minutes $(9.6 \pm 3.3 \%)$. In the anesthetized group, however, blood volume decreased rapidly, by $9.1 \pm 4.7 \%$ at 60 minutes and $4.1 \pm 3.6 \%$ at 100 minutes. After completion of fluid infusion the blood volume expansion ratio was somewhat higher in the anesthetized than in the wakeful group, but the difference was not statistically significant (Fig. 2).

During fluid infusion after blood donation, the volume expansion ratio $(v-V / V)$ of the fluid space increased in both groups, reaching a maximum 5 minutes after completion of infusion and decreasing gradually thereafter. At the time of maximal increase, the volume expansion ratio was significantly higher in the anesthetized $(10.4 \pm 2.6 \%)$ than in the wakeful (6.6 $\pm 1.6 \%)$ group $(\mathrm{P}<0.05)$. However, the ratios were similar 100 minutes after completion of infusion ( $5.5 \pm 1.4 \%$ vs. $5.6 \pm 1.2 \%$, respectively) (Fig. 3).

Infusion strategy nomograms, showing the relationship between infusion rate and infusion time of various fluid regimens to replace blood lost with Hextend ${ }^{\circledR}$ in both wakeful

Table 2. Changes in Hemoglobin Concentration after Infusion of Fluid

\begin{tabular}{ccc}
\hline Time $(\min )$ & Wakeful group $(\mathrm{n}=8)$ & Anesthetized group $(\mathrm{n}=5)$ \\
\hline 0 & $14.5 \pm 0.7$ & $13.9 \pm 1.0$ \\
5 & $14.0 \pm 0.7$ & $13.1 \pm 1.0$ \\
10 & $13.5 \pm 0.7$ & $12.7 \pm 1.0$ \\
15 & $13.2 \pm 0.8$ & $12.3 \pm 1.2$ \\
20 & $13.0 \pm 0.7$ & $12.2 \pm 1.1$ \\
25 & $12.9 \pm 0.7$ & $12.2 \pm 1.3$ \\
30 & $12.9 \pm 0.6$ & $12.2 \pm 1.2$ \\
40 & $13.0 \pm 0.6$ & $12.4 \pm 1.0$ \\
50 & $13.0 \pm 0.8$ & $12.5 \pm 1.1$ \\
60 & $13.0 \pm 0.7$ & $12.7 \pm 0.9$ \\
80 & $13.1 \pm 0.6$ & $13.3 \pm 1.3$ \\
100 & $13.1 \pm 0.6$ & $13.4 \pm 1.3$ \\
120 & $13.1 \pm 0.8$ & \\
150 & $13.1 \pm 0.5$ & \\
180 & $13.2 \pm 0.6$ & \\
\hline
\end{tabular}

Data are means and standard deviations. 

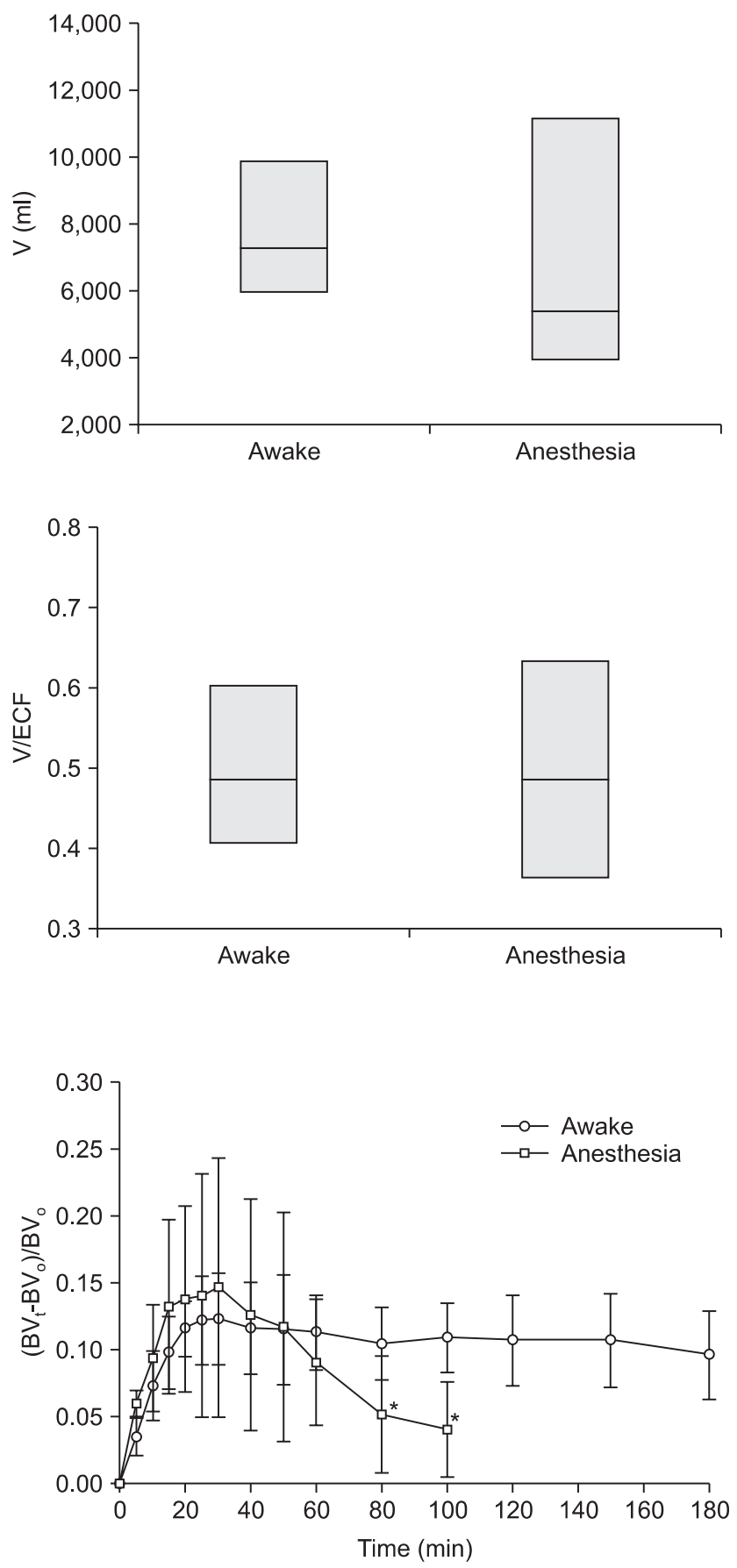

Fig. 2. Changes in blood volume expansion during and after intravenous infusion of $500 \mathrm{ml}$ of Hextend over 20 min after hemorrhage of $400 \mathrm{ml}$ in wakeful $(\bigcirc)$ and desflurane-anesthetized $(\square)$ volunteers. Data are means and standard deviations. $\mathrm{BV}_{\mathrm{t}}$ : blood volume at any time during fluid infusion; $\mathrm{BV}_{0}$ : Baseline blood volume before fluid infusion. $* \mathrm{P}<0.05$ compared with the wakeful group.

and anesthetized subjects, were created by computer simulation using one-compartment volume model kinetic parameters (Fig. 4). These nomograms showed the amount of

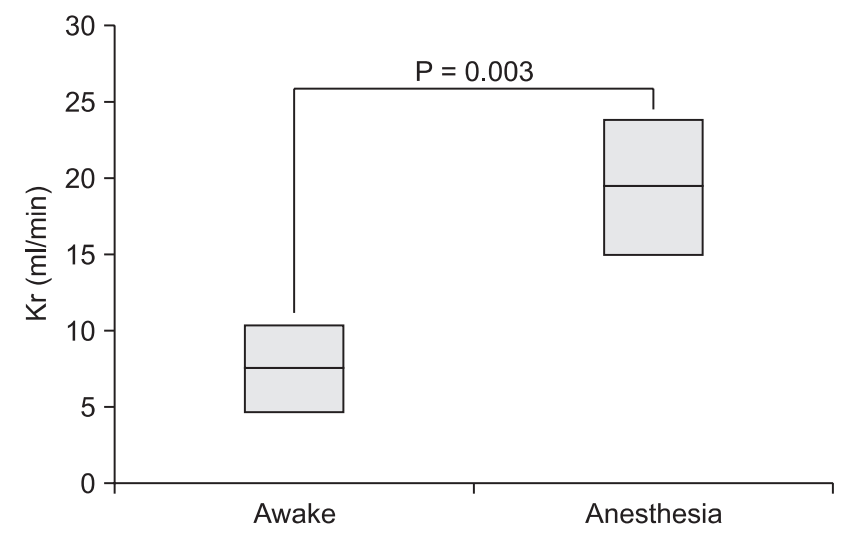

Fig. 1. Fluid kinetic parameters in wakeful and anesthetized Volunteers. Data are median and interqurtile ranges. V: target body fluid space volume, $\mathrm{Kr}$ : elimination rate constant according to volume expansion ratio, ECF: extracellular fluid $(=200 \mathrm{ml} / \mathrm{kg})$.

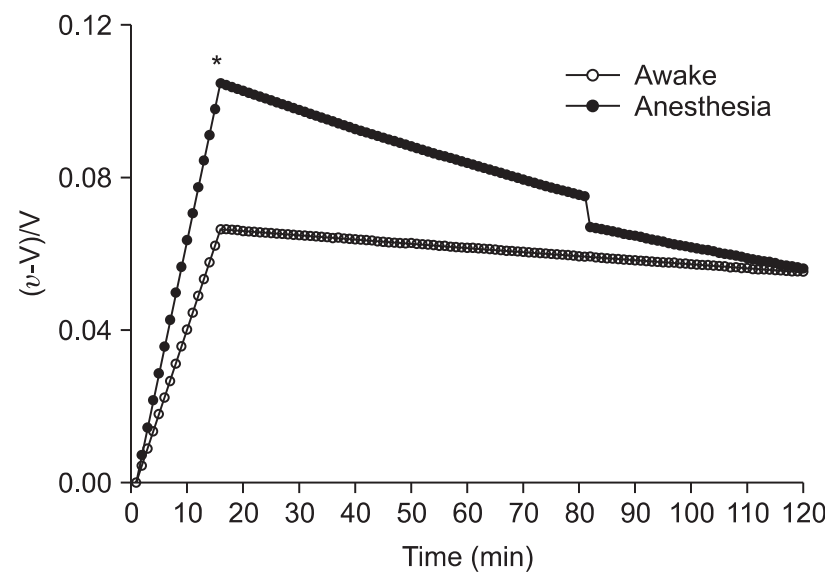

Fig. 3. Fluid kinetic model-predicted dilution-time curve of the primary fluid space during and after intravenous infusion of $500 \mathrm{ml}$ of Hextend over $20 \mathrm{~min}$ after hemorrhage of $400 \mathrm{ml}$ in wakeful $(\bigcirc)$ and desflurane-anesthetized ( volunteers. $v$ : expandable body fluid space, V: baseline body fluid volume. $* \mathrm{P}<0.05$ compared with the wakeful group.

fluid required to reach a predetermined dilution (and/or to restore normovolemia) by combining various infusion rates and infusion times. 
A Relation between infusion rate and infusion time
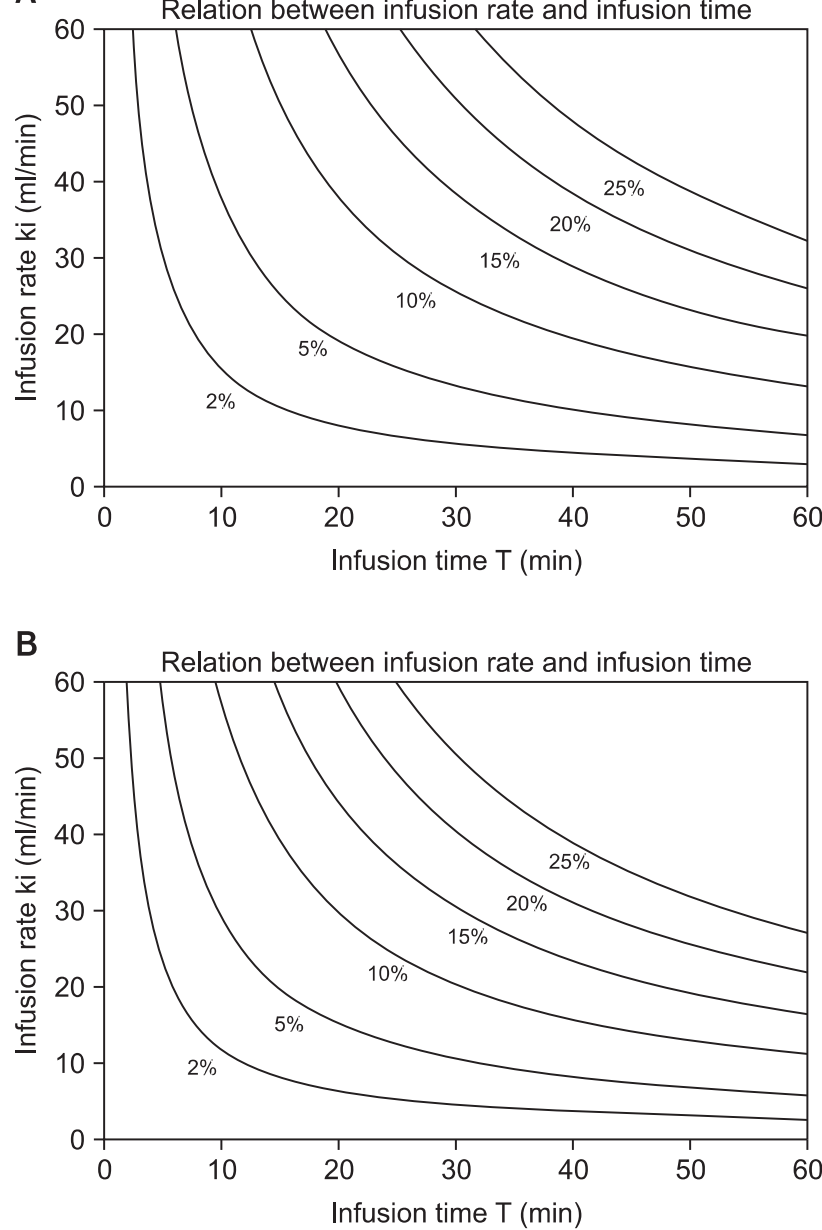
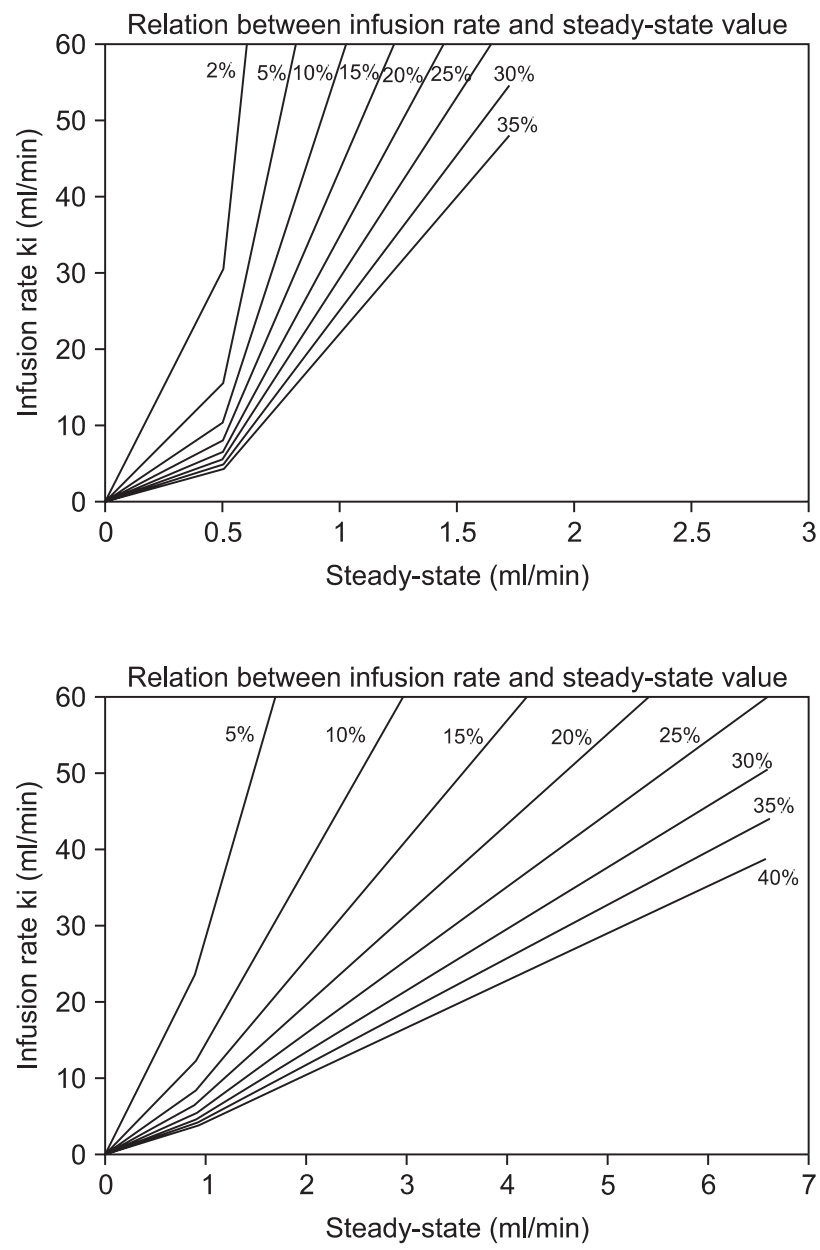

Fig. 4. Infusion strategy nomogram showing (left) the relationship between infusion rate and infusion time and (right) the infusion rate required to maintain a steady-state dilution, estimated from both infusion rate and infusion time during the first phase, with reference to Hextend infusion after mild hypovolemia ( $400 \mathrm{ml})$ in wakeful (A) and anesthetized (B) individuals.

\section{Discussion}

We show here that anesthesia in mildly hypovolemic patients increased $k \mathrm{r}$ values and rapidly decreased the effect of Hextend ${ }^{\circledR}$ on blood volume expansion over time.

If the body fluid space is considered to be a space surrounded by an elastic wall, like a balloon filled with water, and if fluid shifting occurs according to a one- or two-volume space model, then infusion of a crystalloid solution can be interpreted using either space model, whereas infusion of a colloid solution can be interpreted only by employing a one-volume space model $[11,13,16]$. We therefore utilized a one-volume space model in the present study.

Following hemorrhage, a considerable volume of extravascular fluid flows into the intravascular space, powered by a physiological compensatory mechanism termed "transcapillary refill" or "autotransfusion", to compensate for the loss of volume [17]. Factors contributing to transcapillary refill include a decrease in capillary hydrostatic pressure caused by the constriction of arterioli [18], an increase in total intravascular protein [19], a rise in lymphatic flow [17], and movement of interstitial fluid into the intravascular space caused by the osmotic effect of hyperglycemia [20]. Transcapillary refill varies depending on the volume hemorrhaged, the time since hemorrhage, and the use of anesthetics [6,21]. Isoflurane anesthesia has been reported to inhibit compensatory transcapillary refilling after hemorrhage, resulting in decreased expansion of intravascular volume compared with what is seen in wakeful subjects [6]. Following normotensive (15\%) hemorrhage, intravascular volume restoration in anesthetized individuals was only $23 \%$ that of wakeful individuals. Moreover, the rate of transcapillary refill varied from 0 to $11.2 \mathrm{ml} / \mathrm{min}$, depending on the time after hemorrhage and any use of an anesthetic agent, but was most rapid during the first 40 minutes 
after hemorrhage. In addition, although studies have shown that approximately $40 \%$ of bled volume was restored at a rate of $10.5 \mathrm{ml} / \mathrm{min}$ during the first 40 minutes after hypotensive (45\%) hemorrhage, other reports have described much lower volumes and rates. All these factors including physiologic compensation mechanism, the volume hemorrhaged, and anesthesia might affect the kinetics of fluid infusion and the volume requirement after hemorrhage [5].

In the anesthetized state, increased concentrations of renin and aldosterone, systemic hypotension, and renal vasoconstriction have been found to result in a lower glomerular filtration rate (30-50\% that observed in wakeful individuals), a drop in renal blood flow (by $40-60 \%$ ), and a fall in urinary flow rate (by $34 \%$ ), all of which can increase retention of infused fluid [3]. The volume expansion effect of fluid infused after hemorrhage, in both anesthetized and wakeful individuals, may be affected by differences in these factors. The elimination rate constant $(k r)$, representing the clearance of infused fluid from plasma, remained constant in individuals with normal kidney function, unless the amount of infused fluid was extremely large (50 ml/kg) [22]. Moreover, $k \mathrm{r}$ was highly correlated with urinary output. However, surgical stress, anesthetics, and hemorrhage, can all lead to changes in $k \mathrm{r}$ [3-5]. We found that $k \mathrm{r}$ was larger in the anesthetized than in the wakeful group, a finding in conflict with previous reports, which showed that crystalloid infusion after hemorrhage [5] and under anesthesia [4] decreased both urinary output and $k \mathrm{r}$. However, $k \mathrm{r}$ values in anesthetized individuals may represent total elimination from plasma, including both urinary excretion and peripheral accumulation, rather than urinary excretion alone [23]. Our results therefore suggest that, following mild hemorrhage and the infusion of Hextend $^{\circledR}$, fluid elimination from plasma to the extravascular space may be greater in anesthetized than in wakeful patients. However, our results cannot be directly compared with those of other studies, as we did not measure urinary output. Moreover, our results suggest that the volume expansion effect of colloid solution is not sustained during anesthesia, resulting in greater water retention in the extravascular space in anesthetized than in wakeful individuals.

Although the difference was not statistically significant, we found that $V$ values with use of Hextend ${ }^{\circledR}$ infusion were smaller in anesthetized than in wakeful individuals under conditions of mild hypovolemia, and this may reflect extravascular accumulation, even during fluid infusion. The volume expansion ratio of the fluid space was also higher in the anesthetized than in the wakeful group. This may be associated with the larger $k \mathrm{r}$ value observed for anesthetized subjects. If, however, the target volume of anesthetized patients was smaller because of individual variation, the expansion ratio would be greater in this group. These results are consistent with those reported previously [23].

Computer simulations using one-compartment volume kinetic parameters for wakeful and anesthetized individuals (Fig. 3) can be used as nomograms to determine infusion rates and infusion times required to produce a desired dilution of plasma, and to maintain a steady-state dilution after mild blood loss $(400 \mathrm{ml})$. For example, a plasma dilution of $5 \%(\mathrm{v} / \mathrm{v})$ in wakeful individuals requires an infusion rate of $20 \mathrm{ml} / \mathrm{min}$ for $19 \mathrm{~min}$ or $40 \mathrm{ml} / \mathrm{min}$ over $9.5 \mathrm{~min}$ (total, $380 \mathrm{ml}$ ). A subsequent infusion rate of $0.55 \mathrm{ml} / \mathrm{min}$ or $0.7 \mathrm{ml} / \mathrm{min}$, respectively, of additional fluid, would be required to maintain a steadystate plasma dilution of $5 \%(\mathrm{v} / \mathrm{v})$. In anesthetized individuals, however, an infusion rate of $20 \mathrm{ml} / \mathrm{min}$ over $15 \mathrm{~min}$ or $40 \mathrm{ml}$ / min over $7.5 \mathrm{~min}$ (total, $300 \mathrm{ml}$ ) would be required to attain a plasma dilution of $5 \%(\mathrm{v} / \mathrm{v})$, and an infusion rate of $0.8 \mathrm{ml} /$ $\mathrm{min}$ or $1.2 \mathrm{ml} / \mathrm{min}$, respectively, of additional fluid would be required to maintain this dilution. Thus, compared with wakeful individuals, anesthetized patients require smaller volumes of fluid to achieve a given plasma dilution, but higher rates of additional fluid infusion to maintain a steady state. In addition, our nomograms (Fig. 3) are valid for colloid fluid replacement after mild blood loss ( $400 \mathrm{ml}$ ) only in wakeful and anesthetized healthy individuals. Thus, caution should be exercised when applying our nomograms to other conditions, such as severe blood loss, in which situations the volume kinetics might be different.

This study had several limitations. First, precise comparison between the two groups was difficult because autologous blood was transfused during BM donation, before the infusion of colloid, in anesthetized individuals, although the total volume of blood loss was the same in both wakeful and anesthetized individuals. This may have affected the volume kinetics of the infused solution. Secondly, because hypotension per se may affect water retention and fluid kinetics [7], different results may have been obtained following the loss of large amounts of blood, leading to hypotension. Hence, our findings in individuals with mild hypovolemia should not be extrapolated to those with moderate or massive hemorrhage.

In conclusion, we utilized volume kinetic analysis to compare the effects of colloid infusion on volume expansion in mildly hypovolemic anesthetized and wakeful individuals. We found that such infusion had similar effects of volume expansion in the two groups, but the volume expansion effect rapidly decreased in the anesthetized group. Because the elimination rate constant was significantly larger in the anesthetized than in the wakeful group, leading to increased extravascular water retention in the former subjects, care should be taking when infusing colloids during anesthesia. The nomograms created from parameters of our fluid kinetic model may be useful in guiding fluid infusion after mild hemorrhage. 


\section{References}

1. Ernest D, Belzberg AS, Dodek PM. Distribution of normal saline and 5\% albumin infusions in cardiac surgical patients. Crit Care Med 2001; 29: 2299-302.

2. Mcllroy DR, Kharasch ED. Acute intravascular volume expansion with rapidly administered crystalloid or colloid in the setting of moderate hypovolemia. Anesth Analg 2003; 96: 1572-7.

3. Norberg A, Hahn RG, Li H, Olsson J, Prough DS, Borsheim E, et al. Population volume kinetics predicts retention of $0.9 \%$ saline infused in awake and isoflurane-anesthetized volunteers. Anesthesiology 2007; 107: 24-32.

4. Connolly CM, Kramer GC, Hahn RG, Chaisson NF, Svensen CH, Kirschner RA, et al. Isoflurane but not mechanical ventilation promotes extravascular fluid accumulation during crystalloid volume loading. Anesthesiology 2003; 98: 670-81.

5. Norberg A, Brauer KI, Prough DS, Gabrielsson J, Hahn RG, Uchida T, et al. Volume turnover kinetics of fluid shifts after hemorrhage, fluid infusion, and the combination of hemorrhage and fluid infusion in sheep. Anesthesiology 2005; 102: 985-94.

6. Hahn RG, Brauer L, Rodhe P, Svensen CH, Prough DS. Isoflurane inhibits compensatory intravascular volume expansion after hemorrhage in sheep. Anesth Analg 2006; 103: 350-8.

7. Ewaldsson CA, Hahn RG. Kinetics and extravascular retention of acetated ringer's solution during isoflurane or propofol anesthesia for thyroid surgery. Anesthesiology 2005; 103: 460-9.

8. Hahn RG. Volume effect of Ringer's solution in the blood during general anaesthesia. Eur J Anaesthesiol 1998; 15: 427-32.

9. Ewaldsson CA, Hahn RG. Volume kinetics of Ringer's solution during induction of spinal and general anaesthesia. $\mathrm{Br} \mathrm{J}$ Anaesth 2001; 87: 406-14.

10. Chappell D, Jacob M, Hofmann-Kiefer K, Conzen P, Rehm M. A rational approach to perioperative fluid management. Anesthesiology 2008; 109: 723-40.

11. Lee EH, Lee JY, Yeo YG, Choi KT. Modeling the expandable body fluid space after I.V. fluid infusion. Korean J Anesthesiol 2006; 51:
36-43.

12. Hahn RG. A haemoglobin dilution method (HDM) for estimation of blood volume variations during transurethral prostatic surgery. Acta Anaesthesiol Scand 1987; 31: 572-8.

13. Kang SJ, Choi KT, Lee JH, Lee DH. Assessment of fluid space after infusion of hartmann's solution and hydroxyethyl starch solutions during general anesthesia. Korean J Anesthesiol 2008; 54: 300-6.

14. Drobin D, Hahn RG. Volume kinetics of Ringer's solution in hypovolemic volunteers. Anesthesiology 1999; 90: 81-91.

15. Choi KT, Yeo YK. Kinetics of volume expansion during infusion of Ringer's solution based on single volume model. Korean J Chem Eng 2006; 23: 610-6.

16. Hahn RG. The use of volume kinetics to optimize fluid therapy. J Trauma 2003; 54: S155-8.

17. Drucker WR, Chadwick CD, Gann DS. Transcapillary refill in hemorrhage and shock. Arch Surg 1981; 116: 1344-53.

18. Lundvall J, Hillman J. Fluid transfer from skeletal muscle to blood during hemorrhage. Importance of beta adrenergic vascular mechanisms. Acta Physiol Scand 1978; 102: 450-8.

19. Darlington DN, Jones RO, Magnuson TA, Gann DS. Role of intestinal fluid in restitution of blood volume and plasma protein after hemorrhage in awake rats. Am J Physiol 1995; 268: R715-22.

20. Jarhult J, Holmberg J, Lundvall J, Mellander S. Hyperglycemic and hyperosmolar responses to graded hemorrhage. Acta Physiol Scand 1976; 97: 470-5.

21. Moore FD, Dagher FJ, Boyden CM, Lee CJ, Lyons JH. Hemorrhage in normal man. I. distribution and dispersal of saline infusions following acute blood loss: clinical kinetics of blood volume support. Ann Surg 1966; 163: 485-504.

22. Svensen CH, Brauer KP, Hahn RG, Uchida T, Traber LD, Traber $\mathrm{DL}$, et al. Elimination rate constant describing clearance of infused fluid from plasma is independent of large infusion volumes of $0.9 \%$ saline in sheep. Anesthesiology 2004; 101: 666-74.

23. Brauer KI, Svensen C, Hahn RG, Traber LD, Prough DS. Volume kinetic analysis of the distribution of $0.9 \%$ saline in conscious versus isoflurane-anesthetized sheep. Anesthesiology 2002; 96: 442-9. 